had low toxicity and gave an overall response rate of $73 \%$. In the multicentre study in 153 patients there were no drug-related deaths.

We conclude that intracavitary bleomycin is well tolerated and is effective as palliative treatment for malignant effusions, preventing the need for frequent aspiration of accumulated fluid. Because of its lack of haematological toxicity it may be used safely in the already leucopenic patient.

M J OsTROWSKI

Department of Radiotherapy and

Oncology,

Norfolk and Norwich Hospital,

Norwich NR1 3SR

G M Halsal

Medical Services,

Lundbeck Limited,

1 Anderson CB, Philpott GW, Ferguson TB. Cancer $1974 ; 33: 916-22$.

' Paladine W, Cunningham TJ, Sponzo R, Donavan M, Olson K, Horton J. Cancer 1976;38:1903-8.

Trotter JM, Stuart JFB, McBeth F, McVie JG,
Calman KC. Br $\mathcal{f}$ Cancer 1979;40:310.

\section{Porphyria cutanea tarda and}

beta-thalassaemia minor

SIR,-We have read with interest the report by Dr R W G Chapman (24 May, p 1255) of cases of porphyria cutanea tarda in a mother and daughter with beta-thalassaemia minor We note that alcohol intake was not excessive and that the mother had not taken oestrogens however, in view of the Turkish nationality of the mother we wonder whether she and her daughter could have been exposed to any other agent capable of precipitating the disease. We are thinking in particular of the hexachlorobenzene-induced outbreak of porphyria cutanea tarda in Turkey which occurred from 1956 to $1961 .^{1}$ Some people exposed during this intoxication are still showing symptoms ${ }^{2}$; if the patients were in southeastern Turkey during the relevant period then hexachlorobenzene poisoning could be contributory to the disturbance of porphyrin metabolism in these patients.

A G SMITH

MRC Toxicology Unit,

Medical Research Council

Laboratories,
Carshalton, Surrey SM5 4EF.

Cam C, Nigogosyan G. $\mathcal{F} A M A$ 1963;183:88-91. Cripps DJ, Gocmen A, Peters HA. Arch Dermatol
$1980 ; 116: 46-50$.

* *We sent a copy of this letter to Dr Chapman, whose reply is printed below.-ED, $B M \mathcal{H}$.

SIR,-I would like to answer the points raised in the letter from Drs Smith and Grieg regarding the cases which I reported of porphyria cutanea tarda in a mother and daughter with beta-thalassaemia minor.

There was no history in either case of exposure to agents known to precipitate porphyria cutanea tarda. Although Turkish, neither patient has ever lived in or visited south-eastern Turkey, and during the period of the outbreak of the disease caused by hexachlorobenzene-poisoned wheat (1956-62) neither patient was living in Turkey. I believe therefore that in both patients iron overload due to beta-thalassaemia trait with haemolysi remains the most likely precipitating factor.

Roger ChapMaN

David M Graham-SERVICE

**'The BMA Council debated proposals for a special BUPA scheme for BMA members at its last meeting (28 June, p 1633). A recommendation has gone to the Repre sentative Body to approve the scheme and to offer it to members as well as the existing

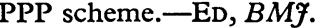

\section{Student electives overseas}

SIR,-I would like to support the suggestion from Dundee by Ruth A Cruickshank and Dr D B Walsh (7 June, p 1359) that more help should be given to students arranging to spend their elective period of study in a foreign country.

Apart from the problem of finding a suitable venue, there is the problem of transport. The
Sunday Times magazine (15 June) shows that there are 30 different fares from London to Los Angeles. Even experienced agents cannot always find the best bargain out of this mess. Last year some students had to pay again for the return journey, when the airline refused to honour the return tickets. Since the airline did not belong to the International Air Transport Association they could not get their money back on return to England.

It might be a profitable method of recruitment of future members if the BMA could give unbiased advice to medical students on the cheapest and safest airlines to use for various destinations.

TOM WHITE

Croydon CR9 7AA

\section{Health hazards from nuclear industry}

SIR,-I was interested to see the letter by Dr Robin Andrews (31 May, p 1323) in which he called for the BMA to act as a watchdog over the health aspects of the nuclear industry. As the National Radiological Protection Board has performed this role for some 10 years I was a little surprised.

The NRPB was set up under the Radiological Protection Act 1970 with the specific functions of advancing knowledge about the protection of mankind from radiation hazards (for example, by research) and of providing advice and information to persons (including government departments) with responsibilities for radiological protection. The board is also empowered to provide technical services and to charge for those services. It is independent of industry and other users of radiation, and of the regulatory bodies and the pressure groups.

Of course, if the BMA decides to take on a role in this field we would be pleased to co-operate with it. But I should be surprised if members of the BMA who know us well would feel that such an initiative on the part of the BMA is necessary.

M J Gaines

National Radiological Protection

Harwell, Didcot OX11 ORQ

\section{Drug firms and doctors}

SIR,-To my surprise a respected drug representative recently offered me money and a free trip to the Continent, in return for joining a drug trial organised by his company. The "trial" seemed to me to be designed to provide commercially useful data rather than medical information? Two questions occur: (1) Is there a lot of it about? (2) Do some authors of papers on drugs accept gifts from the manufacturers without declaring the fact in their articles?

Incidentally is was interesting to learn my price, but not very flattering.

BRUCE SimpSON

Cambridge Military Hospital,

\section{Correction}

\section{Vitamin $D_{3}$ in osteoporosis}

We regret that in the letter by Dr I Wandless et al (31 May, p 1320) there was an error in line 4 of the second paragraph, where mg should be $\mu \mathrm{g}$. 